\title{
Phosphorylation of the Postsynaptic Density-95 (PSD-95)/Discs Large/Zona Occludens-1 Binding Site of Stargazin Regulates Binding to PSD-95 and Synaptic Targeting of AMPA Receptors
}

\author{
Dane M. Chetkovich, ${ }^{1 *}$ Lu Chen, ${ }^{2 *}$ Timothy J. Stocker, ${ }^{3}$ Roger A. Nicoll, ${ }^{2,3}$ and David S. Bredt ${ }^{3}$ \\ Departments of ${ }^{1}$ Neurology, ${ }^{2}$ Cellular and Molecular Pharmacology, and ${ }^{3}$ Physiology, University of California at San \\ Francisco, San Francisco, California 94143
}

\begin{abstract}
Dynamic regulation of AMPA-type receptors at the synapse is proposed to play a critical role in alterations of the synaptic strength seen in cellular models of learning and memory such as long-term potentiation in the hippocampus. Stargazin, previously identified as an AMPA receptor (AMPAR)-interacting protein, is critical for surface expression and synaptic targeting of AMPARs. Stargazin interacts with postsynaptic density-95/ discs large/zona occludens-1 (PDZ) proteins via a C-terminal PDZ binding motif. Interestingly, the $\mathrm{C}$ terminal of stargazin also predicts phosphorylation at a threonine residue critical for PDZ protein binding. Because protein phosphorylation regulates synaptic plasticity, we characterized this site and the effects of stargazin phosphorylation on AMPAR function. In vitro peptide phosphorylation assays and Western blot analysis with
\end{abstract}

phospho-stargazin-specific antibodies indicate that the critical threonine within the stargazin PDZ binding site is phosphorylated by protein kinase $A$. This phosphorylation disrupts stargazin interaction and clustering with postsynaptic density-95 (PSD-95) in transfected COS-7 cells. Furthermore, a stargazin construct with a Thr-to-Glu mutation that mimics phosphorylation fails to cluster at synaptic spines and downregulates synaptic AMPAR function in cultured hippocampal neurons. These data suggest that phosphorylation of the stargazin PDZ ligand can disrupt stargazin interaction with PSD-95 and thereby regulate synaptic AMPAR function.

Key words: AMPA receptors; PSD-95; PDZ domain; phosphorylation; glutamate; plasticity
Glutamate receptors (GluRs) mediate most excitatory synaptic transmission in the brain. There are two major classes of ionotropic receptors at glutamatergic synapses, NMDA receptors (NMDARs) and AMPA receptors (AMPARs). AMPARs mediate rapid synaptic transmission, whereas activation of calciumpermeable NMDARs induces synaptic plasticity (Madison et al., 1991; Nakanishi, 1992; Bliss and Collingridge, 1993; Seeburg, 1993; Hollmann and Heinemann, 1994). Both AMPA and NMDARs are highly concentrated at the postsynaptic density (PSD) of excitatory synapses, yet there are remarkable differences in the synaptic anchoring of NMDA and AMPARs. Whereas NMDARs are stable components of the PSD, AMPARs recycle rapidly; changes in the synaptic expression of AMPARs regulate aspects of synaptic plasticity (Song et al., 1998; Luthi et al., 1999; Ehlers, 2000; Liu and Cull-Candy, 2000; Lüscher et al., 2000; Malinow et al., 2000; Man et al., 2000).

This differential behavior of synaptic AMPA versus NMDAR

Received March 21, 2002; revised April 24, 2002; accepted April 29, 2002.

This work was supported by grants from the National Institutes of Health (D.S.B, R.A.N., D.M.C. L.C.), the Howard Hughes Medical Institute Research Resources Program (D.S.B.), the Christopher Reeve Paralysis Foundation (D.S.B.), the Human Frontier Research Program (D.S.B.), Bristol-Myers-Squibb Company (R.A.N.), and the National Association for Research on Schizophrenia and Depression (D.M.C.). R.A.N. is a member of the Keck Center for Integrative Neuroscience and the Silvo Conte Center for Neuroscience Research. D.S.B. is an established investigator for the American Heart Association.

This work was presented in abstract form at the Society for Neuroscience annual meeting, November 2001.

*D.M.C. and L.C. contributed equally to this work.

Correspondence should be addressed to Dr. David S. Bredt, University of California at San Francisco School of Medicine, Box 0444, 513 Parnassus Avenue, San Francisco, CA 94143-0444. E-mail: bredt@itsa.ucsf.edu.

Copyright (C) 2002 Society for Neuroscience 0270-6474/02/225791-06\$15.00/0 proteins likely reflects their different anchoring mechanisms at the PSD, because the cytosolic C-terminal tails of AMPA and NMDARs associate with distinct PSD-95/discs large/zona occludens-1 (PDZ) domain-containing synaptic scaffolding proteins (Kornau et al., 1997; Ziff, 1997; Garner et al., 2000). The C termini of NMDAR NR2 subunits (SIESDV) bind to PDZ domains of the PSD-95/synapse-associated protein-90 family of membrane-associated guanylate kinases (Kornau et al., 1997; Garner et al., 2000). In contrast, the C-terminal tail of GluR2 (IESVKI) binds to PDZ domains from several proteins, including protein interacting with $\mathrm{C}$ kinase 1 (PICK1), glutamate receptor interacting protein (GRIP), and AMPA receptor binding protein (Srivastava et al., 1998; Kim and Huganir, 1999).

AMPAR subunits also interact with stargazin (Chen et al., 2000), the protein that is mutated in epileptic stargazer mice (Letts et al., 1998). Stargazin has a cytosolic C-terminal tail containing a PDZ binding site (RRTTPV) that interacts with PSD-95 (Chen et al., 2000). Stargazin is enriched in cerebellar granule cells, and AMPARs fail to traffic to the plasma membrane or to the synapse in stargazer mutant granule cells. Stargazin-like mechanisms may also regulate AMPARs in the forebrain, because overexpression of a dominant negative stargazin construct reduces synaptic AMPAR function in hippocampal neurons (Chen et al., 2000). Therefore, these previous studies identify a necessary role for stargazin in plasma membrane expression of AMPARs. How stargazin regulates cycling of AMPARs remains unclear (Tomita et al., 2001).

Protein phosphorylation plays a central role in controlling AMPAR expression at the synapse and in regulating synaptic 
strength (Lüscher et al., 1999; Lee et al., 2000; Malinow et al., 2000; Soderling, 2000). Interestingly, stargazin and its close homologs all contain a consensus sequence for protein kinase phosphorylation within their PDZ binding site. Therefore, we explored phosphorylation of this site and its possible regulation of AMPAR trafficking. We found that the critical threonine within the stargazin PDZ binding site can be phosphorylated by protein kinase A (PKA). This phosphorylation disrupts stargazin interaction and clustering with PSD-95. Stargazin with a Thr-to-Glu mutation that mimics phosphorylation does not cluster at synapses; this phospho-mimic blocks the synaptic function of AMPARs in transfected neurons. These data suggest that phosphorylation of the stargazin PDZ ligand provides a mechanism for disrupting stargazin interaction with PSD-95, thereby regulating synaptic AMPARs.

\section{MATERIALS AND METHODS}

Antibodies. The stargazin C-terminal peptide star(313-323) and its phospho-amino acid (Thr321) analog phospho-star(313-323), coupled to the maleimide-activated keyhole limpet hemocyanin, were used for rabbit immunization.

In vitro kinase assays. Kinase reactions were done in $50 \mu \mathrm{l}$ of assay buffer containing [final concentration: 25 mM MES, pH 6.0, 1 mM EDTA, $1 \mathrm{~mm}$ EGTA, $1 \mathrm{~mm} \beta$-mercaptoethanol, $0.05 \%$ Triton X-100, protease inhibitors $(10 \mu \mathrm{g} / \mathrm{ml}$ leupeptin and $2 \mu \mathrm{g} / \mathrm{ml}$ aprotinin), phosphatase inhibitors ( $2 \mathrm{mM} \mathrm{Na}_{4} \mathrm{P}_{2} \mathrm{O}_{7}$ and $10 \mu \mathrm{M} \mathrm{NaF}$ ), $5 \mathrm{mM} \mathrm{MgCl} \mathrm{Mg}_{2}, 20 \mu \mathrm{M}$ ATP, and $\left.\sim 3000 \mathrm{cpm} / \mathrm{pmol}\left[\gamma_{-}{ }^{32} \mathrm{P}\right] \mathrm{ATP}\right]$. Peptide substrates were added at a final concentration of $500 \mu \mathrm{M}$. The peptide substrates used included Leu-Arg-Arg-Ala-Ser-Leu-Gly (Kemptide; Sigma, St. Louis, MO), MetAsp-Cys-Leu-Cys-Ile-Val-Thr-Thr-Lys-Lys-Tyr-Arg-Tyr-Gln-Asp-GluAsp-Thr-Pro (PSD-95 1-20; Research Genetics, Huntsville, AL), and the stargazin $\mathrm{C}$-terminal peptides described above. Reactions were performed at $30^{\circ} \mathrm{C}$ for $5 \mathrm{~min}$ and stopped with $25 \mu \mathrm{l}$ of ice-cold stop solution (225 $\mathrm{mm} \mathrm{H}_{3} \mathrm{PO}_{4}$ and $1 \mathrm{~mm}$ ATP). Aliquots were spotted onto duplicate phosphocellulose paper strips, washed, and counted.

cDNA cloning and mutagenesis. Constructs coding for PSD-95, $\mathrm{K}_{\mathrm{v}} 1.4$, and stargazin, as well as their green fluorescent protein (GFP) or hemagglutinin (HA) fusions, have been described previously (Topinka and Bredt, 1998; Craven et al., 1999). Stargazin(T321E) and stargazin(R318,319A) were generated by PCR using standard methods.

Yeast two-hybrid assays. Directed yeast two-hybrid assays were performed using the Matchmaker kit (Becton Dickinson, San Jose, CA), according to the manufacturer's protocols. Briefly, engineered stargazin constructs described above were transformed into yeast (AH109) with PDZ I-III of PSD-95 under appropriate selection. Interaction was scored as positive when colonies grew on media lacking Leu, Trp, His, and adenine.

Cell transfection and immunofluorescence labeling. COS-7 cells were grown and transfected using Lipofectamine reagent as described previously (Chen et al., 2000). Hippocampal cultures were maintained, transfected, and stained as described previously (Craven et al., 1999).

Electrophysiology. Whole-cell patch-clamp recordings were performed on cultured neurons as described previously (Chen et al., 2000).

\section{RESULTS}

The consensus sequence for phosphorylation by PKA is Arg-Arg$\mathrm{Xxx}$-Ser/Thr, which is precisely conserved at the $\mathrm{C}$ termini of the stargazin family of proteins (Fig. $1 A$ ). Using in vitro peptide kinase assays (Fig. $1 B$ ), we found that the stargazin $\mathrm{C}$ terminal is phosphorylated by PKA. Phosphorylation of the stargazin peptide occurs specifically on the Thr at position -2 (T321E); a synthetic peptide phosphorylated at this Thr is not a substrate for PKA (Fig. 1B).

To evaluate possible phosphorylation of this site in intact cells, we generated a phospho-specific antibody to the $\mathrm{C}$ terminal of stargazin. We characterized the specificity of this phosphoantibody by dot blot analysis. As shown in Figure $1 C$, the phospho-specific antibody shows $\sim 100$-fold greater reactivity
A

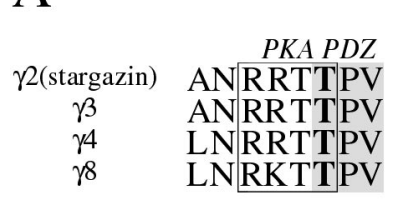

C
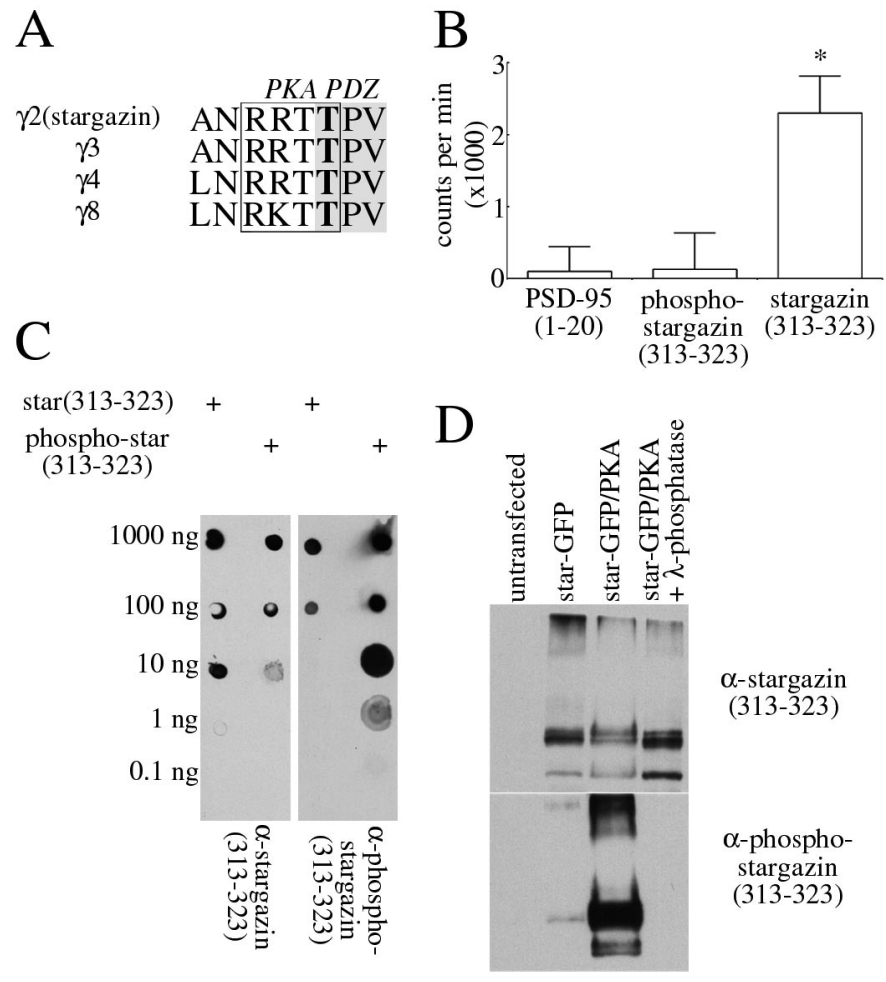

Figure 1. Stargazin is phosphorylated at the PDZ binding site by PKA. $A$, The $\mathrm{C}$-terminal amino acid sequence of stargazin $(\gamma 2)$ as well as other stargazin family members that contain predicted PDZ binding domains. The PDZ binding domain is highlighted in gray, the protein kinase consensus phosphorylation sequence is bordered by a rectangle, and the predicted phosphorylation site and critical PDZ-binding residue are in bold type. B, Peptide substrates were incubated with PKA and $\left[\gamma_{-}-{ }^{32} \mathrm{P}\right] \mathrm{ATP}$ in vitro. Although peptides corresponding to the N-terminal 20 aa of PSD-95 [PSD-95(1-20)] and the C terminal of stargazin phosphorylated at the -2 threonine residue [phospho-stargazin(313-323)] were not phosphorylated, the C terminus of stargazin [stargazin(313-323)] was phosphorylated. Data are presented as counts per minute and represent the average of four experiments \pm SEM. ${ }^{*} p<0.001$. C, Stargazin(313-323) and phospho-stargazin(313-323) were coupled to BSA, spotted on polyvinylidene difluoride membranes, and immunoprobed. Antibodies prepared to phospho-stargazin(313-323) were 100-fold more sensitive for the phosphorylated peptide compared with the nonphosphorylated peptide. $D$, COS-7 cells were transfected with stargazin-GFP (star-GFP) in the presence or absence of PKA-GFP; cell lysates were prepared and subjected to SDS-PAGE and Western blotting with stargazin and phosphostargazin antibodies. Cotransfection with PKA dramatically increased the phosphorylation of stargazin, an effect that was eliminated by treatment of the lysates with $\lambda$-phosphatase.

with the phosphorylated stargazin C-terminal peptide compared with the nonphosphorylated peptide. To evaluate possible phosphorylation of stargazin in intact cells, we transfected COS-7 cells with stargazin and probed immunoblots with the phosphospecific antibody. We found that the PDZ binding site of stargazin is basally phosphorylated in transfected cells. This basal phosphorylation of stargazin is dramatically enhanced by cotransfecting COS-7 cells with the catalytic subunit of PKA. The phospho-specific antibody reacts only with phosphorylated stargazin, because treating the cell extracts with $\lambda$-phosphatase eliminates the reactive band.

Because the PKA phosphorylation site at the $\mathrm{C}$ terminal of stargazin overlaps with the PDZ binding site (Fig. $1 A$ ), one might predict that this phosphorylation would disrupt binding to PSD95. To test this, we first generated a phospho-mimic construct in 
A

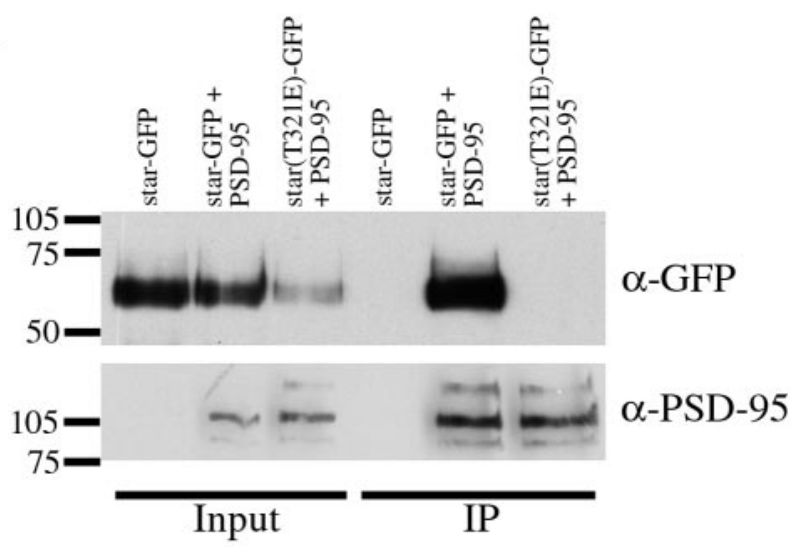

B

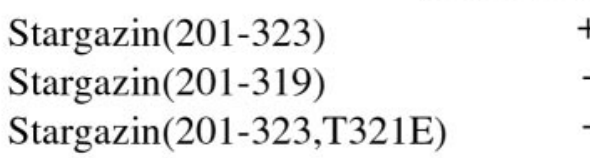

Figure 2. The phospho-mimic stargazin does not interact with PSD-95. $A$, COS-7 cells were transfected alone or with the indicated combinations of stargazin-GFP (star-GFP), PSD-95, and stargazin(T321E)-GFP [star(T321E)-GFP]; cell lysates were prepared, and PSD-95 was immunoprecipitated $(I P)$. Whereas stargazin-GFP interacted strongly with PSD95, stargazin(T321E)-GFP failed to coimmunoprecipitate. $B$, Interaction of stargazin constructs with the PDZ domains of PSD-95. Yeasts were transformed with plasmids encoding the $\mathrm{C}$ terminal of stargazin [stargazin(201-323)], stargazin missing the last four amino acids [stargazin(201$319)]$, or the phospho-mimic stargazin [stargazin(201-323,T321E)], together with PDZ domains I-III of PSD-95. The stargazin C termini were fused to the galactosidase-4 (GAL4) DNA binding domain and the PDZ domains were fused to the GAL4 activation domain. Colonies that grew on plates lacking Leu, Trp, adenine, and His were scored as positive (+).

which the Thr residue (T321) is mutated to Glu (E). This sort of Thr-to-Glu mutation often simulates the effect of phosphorylation by imparting an appropriate negative charge. To test directly whether this construct binds PSD-95, we performed coimmunoprecipitation assays in transfected COS-7 cells. Although wild-type stargazin interacts strongly with PSD-95, the stargazin(T321E) construct showed no interaction (Fig. $2 A$ ). Furthermore, in the yeast two-hybrid assay, the stargazin T321E mutation disrupts binding to the PDZ domains of PSD-95 (Fig. 2B). To test whether phosphorylation of this site regulates binding in intact cells, we used a clustering assay in heterologous cells. COS-7 cells were first transfected with either stargazin-GFP, stargazin(T321E)GFP, stargazin(R318,319A)-GFP, or PSD-95. In these single transfections, each protein showed a generally diffuse distribution with some perinuclear accumulation (data not shown). Cotransfection of PSD-95 with stargazin-GFP produced characteristic patchy clusters of both proteins (Fig. $3 A-C$ ), which are on the plasma membrane, as we demonstrated previously (Chen et al., 2000). In contrast, cotransfection of phospho-mimic stargazin(T321E) with PSD-95 showed diffuse staining of both proteins throughout the cell (Fig. $3 D-F$ ). To assess the role of PKA directly, we transfected cells with PSD-95, stargazin, and PKA-GFP. In these triple transfections, PKA eliminates the clustering of stargazin by PSD-95 (Fig. 3G-I). To control for the effects of PKA, we mutated the pair of Arg residues in the C-terminal tail of stargazin to Ala. This stargazin(R318,319A)-
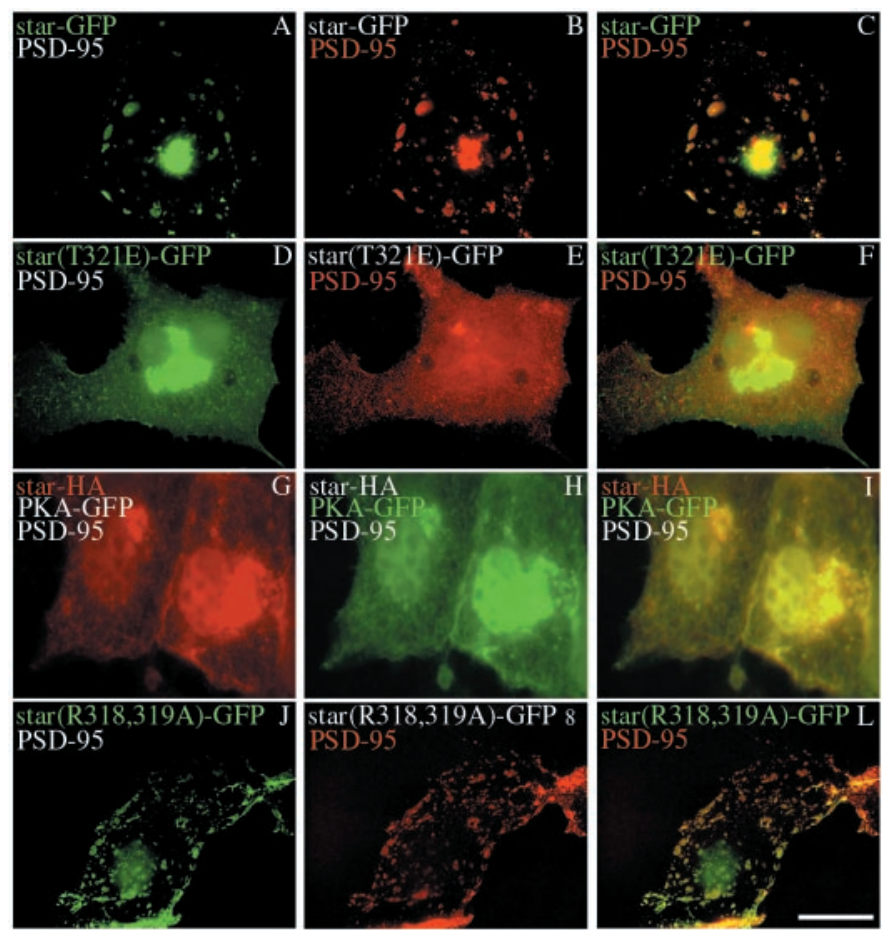

M

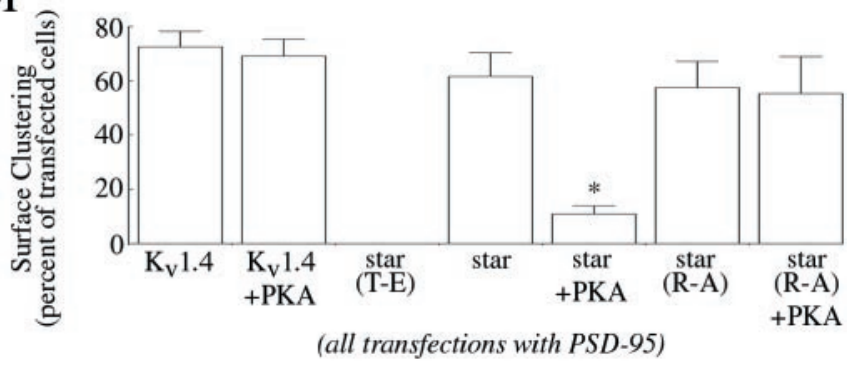

Figure 3. Phosphorylation of the stargazin PDZ ligand disrupts clustering with PSD-95. COS-7 cells were transfected with combinations of stargazin-GFP, stargazin-HA, PSD-95, stargazin(T321E)-GFP, stargazin(R318,319A)-GFP, and PKA-GFP. $A-C$, When cotransfected, PSD-95 and stargazin-GFP cocluster in large plasma membrane patches. $D-F$, Stargazin(T321E)-GFP remains diffusely localized when transfected with PSD-95. $G-I$, Transfection of PKA-GFP with stargazin-HA and PSD-95 results in the diffuse localization of stargazin. $J-L$, Stargazin(R318,319A)-GFP, a construct that contains a mutated PKA recognition site, is clustered by PSD-95 in COS-7 cells. Merged images are shown in the panels on the right $(C, F, I, L)$. Scale bar, $10 \mu \mathrm{M} . M$, COS-7 cells were transfected with PSD-95 and the indicated constructs. star, Stargazin-HA; star(T-E), stargazin(T321E)-HA; star(R-A), stargazin(R318,319A)-HA. Surface clustering was assessed in 100 randomly selected cells in four separate experiments. Although PSD-95mediated clustering of stargazin-HA is reduced by PKA-GFP, there is no effect on PSD-95-mediated clustering of stargazin(R318,319A)-HA or $\mathrm{K}_{\mathrm{v}} 1.4-\mathrm{HA} .{ }^{*} p<0.001$

GFP lacks the consensus sequence for PKA phosphorylation but still binds to PSD-95. We found that this construct clusters with PSD-95 (Fig. 3J-L). Furthermore, whereas PKA diminishes the PSD-95-mediated clustering of stargazin, PKA has no effects on the clustering of stargazin(R318,319A) by PSD-95 (Fig. 3M).

Phosphorylation of stargazin at T321 interferes with the PSD95-mediated clustering of stargazin. In addition, Choi et al. (2002) used a phospho-specific antibody to show that stargazin phosphorylated at T321 is enriched in a soluble, nonsynaptic fraction in the brain. To assess the effect of PKA phosphorylation 

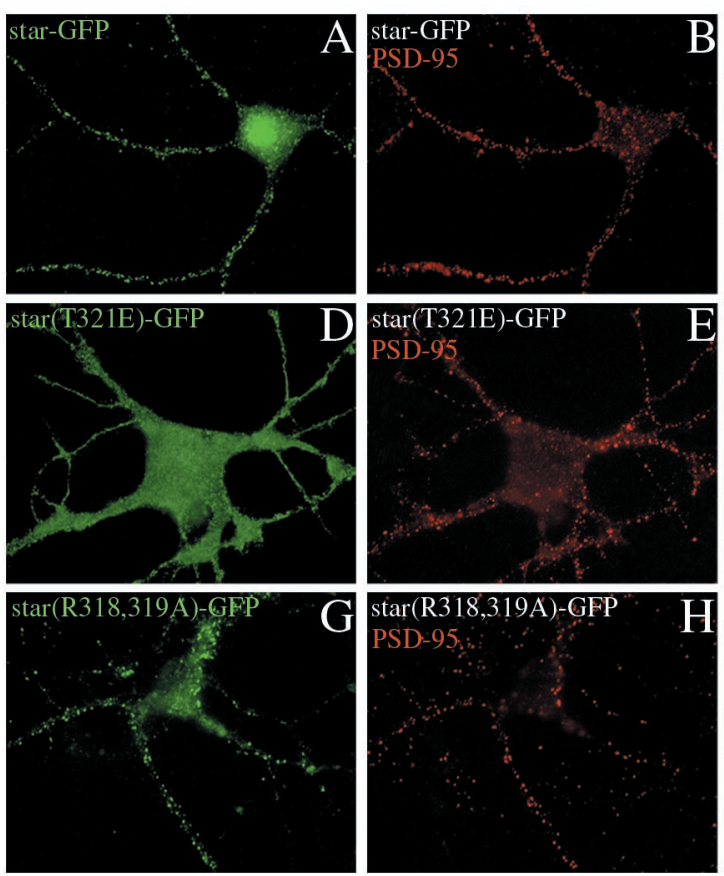
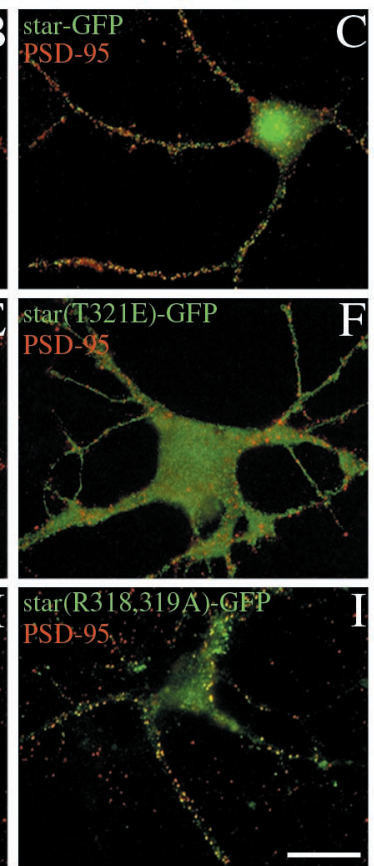

$\mathrm{J}$

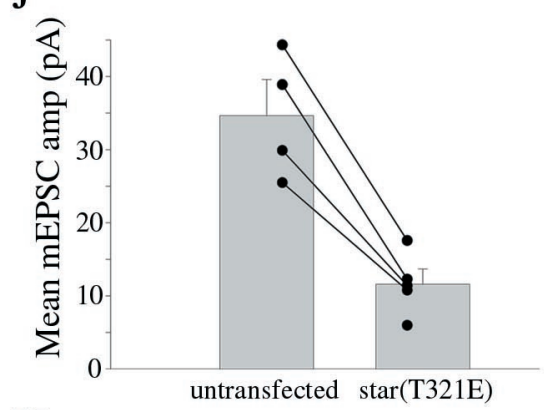

$\mathrm{K}$

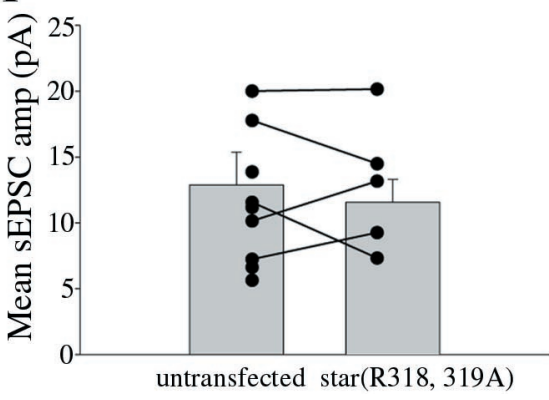

Figure 4. Phospho-mimic stargazin does not traffic to the synapse and attenuates synaptic AMPAR currents. Constructs encoding stargazin-GFP, stargazin(T321E)-GFP, or stargazin(R318,319A)-GFP ( green) were transfected into neurons, which were then fixed and stained for PSD-95 (red) after 11-17 d in vitro. Stargazin-GFP clusters at synaptic sites $(A-C)$. The phospho-mimic stargazin, stargazin(T321E)-GFP, does not target to synapses $(D-F)$, whereas stargazin(R318,319A)-GFP, a construct that contains a mutated PKA recognition site, retains synaptic localization $(G-I)$. Merged images are shown in the panels on the right $(C, F, I)$. Scale bar, $10 \mu \mathrm{M}$. In separate experiments, cultured neurons were transfected with stargazin(T321E)GFP or stargazin(R318,319A)-GFP and synaptic currents were measured by whole-cell patch-clamp recording at a holding potential of $-60 \mathrm{mV}$. Stargazin(T321E)-GFP transfection downregulates AMPAR mEPSC amplitude $(p<0.002)$ in hippocampal neurons $(J)$, whereas stargazin(R318,319A)-GFP has no effect $(K)$.

in the synaptic targeting of stargazin, we transfected hippocampal neurons with GFP-tagged stargazin constructs. Whereas wildtype stargazin clusters at postsynaptic sites in hippocampal neurons (Fig. $4 A-C$ ), stargazin(T321E) with the phospho-mimic at the PKA site showed diffused staining throughout the neuron (Fig. 4D-F). This suggests that phosphorylation of the C-terminal site blocks the synaptic targeting of stargazin. However, the stargazin(R318,319A) construct that lacked the C-terminal PKA phosphorylation site clustered normally in hippocampal neurons (Fig. 4G-I), suggesting that the phosphorylation of stargazin at the $\mathrm{C}$ terminus is not necessary for stargazin synaptic targeting.

To determine whether phosphorylation of stargazin at the $\mathrm{C}$ terminus might play a role in the modulation of AMPAR EPSCs, we transfected cultured hippocampal neurons with the phospho-mimic stargazin(T321E) and evaluated miniature EPSCs (mEPSCs) with whole-cell patch clamp recordings. Stargazin(T321E) expression markedly diminished the amplitude of AMPAR mEPSCs compared with neighboring untransfected neurons (Fig. 4J) [stargazin(T321E), $11.6 \pm 2.1$ $\mathrm{pA}, n=5$; untransfected controls, $34.7 \pm 4.9 \mathrm{pA}, n=4 ; p<$ $0.002]$. In addition, the frequency of mEPSCs was reduced in transfected cells [controls, $11.7 \pm 4.0 \mathrm{~Hz}, n=4$; stargazin(T321E), $3.1 \pm 1.2 \mathrm{~Hz}$ pA, $n=5 ; p<0.05]$.

We also evaluated the effect of transfection of the stargazin(R318,319A) construct lacking the C-terminal PKA phosphorylation site on AMPAR function. This construct had no effect on AMPAR spontaneous EPSC (sEPSC) amplitude in cultured granule cells (Fig. 4J) [stargazin(R318,319A), $12.9 \pm 2.5 \mathrm{pA}, n=5$; untransfected controls, $11.6 \pm 1.7 \mathrm{pA}$, $n=9 ; p>0.5]$. Furthermore, transfection with this construct had no effect on sEPSC frequency [stargazin(R318,319A), $1.2 \pm 0.3 \mathrm{~Hz}, n=5$; untransfected controls, $2.2 \pm 0.6 \mathrm{~Hz}, n=$ $9 ; p>0.2]$.

\section{DISCUSSION}

PDZ domains are small modular protein-protein interaction interfaces that have emerged as critical regulators of protein clustering at synapses and other sites of cell-cell contact (Kornau et al., 1997; Ziff, 1997; Craven and Bredt, 1998; Garner et al., 2000; Kennedy, 2000; Sheng and Sala, 2001). PSD-95 is the major PDZ protein at excitatory synapses in the brain (Kornau et al., 1997; Ziff, 1997; Craven and Bredt, 1998; Garner et al., 2000; Kennedy, 2000; Sheng and Sala, 2001), and PSD-95 binds directly to the C-terminal tail of NMDARs (Kornau et al., 1997). However, overexpression of PSD-95 in hippocampal neurons enhances synaptic AMPARs (El-Husseini et al., 2000). A possible link between PSD-95 and AMPARs is the AMPAR-interacting protein stargazin, a four-pass transmembrane protein that contains a PDZ binding site (Chen et al., 2000). A consensus sequence for protein phosphorylation overlaps the PDZ binding site; this C-terminal cassette is precisely conserved in a family of stargazin-like proteins (Burgess et al., 1999; Klugbauer et al., 2000). In this study, we investigated whether phosphorylation of the C-terminal tail of stargazin might regulate its interaction with PSD-95. We found that this site in stargazin is basally phosphorylated in transfected cells and that this phosphorylation is increased by PKA activity. Phosphorylation of the C-terminal PDZ ligand blocks stargazin binding to and clustering with PSD-95.

Disruption of PSD-95 binding by phosphorylation of the star- 
gazin $C$ terminal can be explained by the crystal structure of the PDZ domain (Doyle et al., 1996), which shows that Thr in the -2 peptide position (the residue phosphorylated in stargazin) forms a critical hydrogen bond to a conserved His residue in the PDZ domain. Phosphorylation of this Thr would disrupt the hydrogen bonding and prevent specific binding. In agreement with our results, previous studies have shown that phosphorylation of inwardly rectifying $\mathrm{K}^{+}$channels (Kir2.0) and $\beta_{2}$-adrenergic receptors at analogous positions in their PDZ binding sites disrupts their binding to type I PDZ domains (Cohen et al., 1996; Cao et al., 1999).

By disrupting its interaction with PSD-95, phosphorylation of the stargazin PDZ domain regulates its synaptic function. Synaptic targeting of AMPARs by stargazin involves two distinct mechanisms (Chen et al., 2000). In cerebellar granular cells from stargazer mice, functional AMPARs are absent from both synaptic and extrasynaptic locations. Intact stargazin can rescue both the synaptic and extrasynaptic AMPARs, whereas stargazin lacking the PDZ binding site selectively rescues extrasynaptic but not synaptic receptors. These data implicate the $\mathrm{C}$ terminal of stargazin specifically in the synaptic targeting of stargazin and its associated AMPARs. Here we find that stargazin with a mimic of constitutive phosphorylation at the $\mathrm{C}$ terminal acts as a dominant negative to suppress synaptic AMPAR function when transfected into wild-type neurons. Paralleling these effects on synaptic AMPARs, we find that the phospho-mimic mutation disrupts synaptic clustering of stargazin in hippocampal neurons. These data suggest that phosphorylation of the PDZ binding ligand of stargazin is a regulator of synaptic levels of AMPARs and synaptic strength.

Recent studies (Song et al., 1998; Luthi et al., 1999; Ehlers, 2000; Liu and Cull-Candy, 2000; Lüscher et al., 2000; Malinow et al., 2000; Man et al., 2000) indicate that changes in the synaptic levels of AMPARs represent a primary mechanism for the rapid modulation of synaptic efficacy, as occurs in some forms of longterm potentiation (LTP) and long-term depression (LTD). Protein phosphorylation cascades play an integral role in this regulation. At hippocampal CA3 to CA1 synapses, LTP requires postsynaptic $\mathrm{Ca} /$ calmodulin-dependent protein kinase II (CaMKII) activity, whereas LTD involves the activation of postsynaptic protein phosphatase cascades (Lee et al., 2000; Lüscher et al., 2000; Malinow et al., 2000; Soderling, 2000). However, at cerebellar parallel fiber to Purkinje cell synapses, LTD requires postsynaptic PKC activity (Xia et al., 2000). The role for PKA in early phase postsynaptic LTP is less well defined; however, recent studies have shown that LTP at depotentiated hippocampal CA3 to CA1 synapses is specifically reduced by PKA inhibitors (Lee et al., 2000). In this light, it may be surprising that phosphorylation of the C-terminal site in stargazin reduces synaptic expression of stargazin and disrupts the synaptic targeting of AMPARs. However, as discussed above, protein kinase regulation of AMPAR levels depends critically on the neuronal type and history of the synapse. Future experiments are needed to determine where and when stargazin phosphorylation integrates into the complex regulatory web.

An alternative model to explain the unexpected consequence of stargazin C-terminal phosphorylation is that other phosphorylation sites in the AMPAR synaptic complex play an overriding role in AMPAR functional modulation. Along these lines, AMPAR function can be potentiated by PKA phosphorylation of serine 845 or by CaMKII or PKC phosphorylation of serine 831 on the intracellular C-terminal tail of the GluR1 subunit of the AMPAR
(Roche et al., 1996; Lee et al., 2000). Furthermore, phosphorylation of the $\mathrm{C}$ terminal of the GluR2 subunit of the AMPAR by PKC has been implicated in de-depression from LTD (Daw et al., 2000). Interestingly, GluR2 phosphorylation by PKC modulates its interactions with the PDZ proteins GRIP1 and PICK1, and PKC-stimulated changes in GRIP1 and PICK1 binding have been implicated in the trafficking of synaptic AMPARs (Chung et al., 2000). Thus, there are multiple phosphorylation substrates that may have differing importance in AMPAR function, depending on kinases, GluR subunits, and the presence or absence of different AMPAR-binding proteins.

Although in our experiments, the C-terminal stargazin phospho-mimic did not target to synapses, it is possible that under physiological circumstances stargazin is phosphorylated after arrival at the synapse. Consistent with this model, we were unable to demonstrate any effect on the synaptic localization of transfected stargazin after stimulation of cultured neurons for up to 30 min with forskolin $(10 \mu \mathrm{M})$ and 3-isobutyl-1-methylxanthine (1 $\mathrm{mm}$ ) (data not shown). Given that GluR2 phosphorylation by PKC can alter its PDZ protein binding specificity, it is interesting to speculate that stargazin phosphorylation at the $\mathrm{C}$ terminal might decrease PSD-95 binding but retain binding to a different interacting molecule or to a less-selective PDZ protein present at the synapse. We have shown previously that stargazin lacking the C-terminal PDZ binding domain retains interaction with GluR subunits (Chen et al., 2000). This observation raises the possibility that phosphorylation at the synapse could release the stargazin/AMPAR from a PDZ-bound state to one in which the mobility of the complex is defined by GluR subunit interaction with proteins such as GRIP1 and PICK1. An alternative explanation for the lack of effect of the pharmacological activation of PKA is that the stargazin phosphorylation site is masked when bound to PSD-95 at synapses, or that exogenous activation of PKA may not behave like endogenous activation. Additional experiments are necessary to determine the role that other stargazin binding partners play in stargazin phosphorylation, as well as stargazin synaptic targeting and AMPAR function.

The specific signal transduction cascades that regulate stargazin phosphorylation in neurons remain uncertain. We were unable to detectably alter the phosphorylation of stargazin by treating cultured hippocampal neurons or hippocampal slices with glutamate (data not shown). These results may reflect technical limitations of this approach or may suggest that activation of excitatory synapses is not directly linked to stargazin phosphorylation. While this manuscript was in preparation, a study published results consistent with our present findings and also showed that stargazin phosphorylated at Thr321 occurs in a soluble fraction exclusive of most PSD proteins (Choi et al., 2002). This observation suggests that synaptic phosphorylation removes stargazin from a PSD-bound state, or alternatively, that cellular rather than synaptic signaling cascades regulate the phosphorylation of stargazin. Finally, the phosphorylation site at the C terminal of stargazin is a consensus for a variety of protein kinases and may be phosphorylated by distinct kinases, depending on the specific cellular and physiological context. Basic amino acids preceding the phosphorylated Thr make this site a candidate for phosphorylation not only by PKA but also by protein kinase $\mathrm{G}$, protein kinase $\mathrm{C}$, and CaMKII. Because proline follows the Thr321, this site may also be phosphorylated by prolinedirected kinases, including MAP kinase and cdk5. Additional work is needed to determine the specific signaling cascades that mediate phosphorylation of the stargazin PDZ binding sites and 
how this participates in the regulation of AMPARs to control synaptic strength and plasticity.

\section{REFERENCES}

Bliss TV, Collingridge GL (1993) A synaptic model of memory: longterm potentiation in the hippocampus. Nature 361:31-39.

Burgess DL, Davis CF, Gefrides LA, Noebels JL (1999) Identification of three novel $\mathrm{Ca}(2+)$ channel gamma subunit genes reveals molecular diversification by tandem and chromosome duplication. Genome Res 9:1204-1213.

Cao TT, Deacon HW, Reczek D, Bretscher A, von Zastrow M (1999) A kinase-regulated PDZ-domain interaction controls endocytic sorting of the $\beta_{2}$-adrenergic receptor. Nature 401:286-290.

Chen L, Chetkovich DM, Petrailia RS, Sweeney NT, Kawaski Y, Wenthold R, Bredt DS, Nicoll RA (2000) Stargazin mediates synaptic targeting of AMPA receptors by two distinct mechanisms. Nature 408:936-943.

Choi J, Ko J, Park E, Lee JR, Yoon J, Lim S, Kim E (2002) Phosphorylation of stargazin by PKA regulates its interaction with PSD-95. J Biol Chem 277:12359-12363.

Chung HJ, Xia J, Scannevin RH, Zhang X, Huganir RL (2000) Phosphorylation of the AMPA receptor subunit GluR2 differentially regulates its interaction with PDZ domain-containing proteins. J Neurosci 20:7258-7267.

Cohen NA, Brenman JE, Snyder SH, Bredt DS (1996) Binding of the inward rectifier $\mathrm{K}+$ channel Kir 2.3 to PSD-95 is regulated by protein kinase A phosphorylation. Neuron 17:759-767.

Craven SE, Bredt DS (1998) PDZ proteins organize synaptic signaling pathways. Cell 93:495-498.

Craven SE, Husseini AE, Bredt DS (1999) Synaptic targeting of the postsynaptic density protein PSD-95 mediated by lipid and protein motifs. Neuron 22:497-509.

Daw MI, Chittajallu R, Bortolotto ZA, Bortolotto D, Duprat F, Henley JM, Collingridge GL, Isaac JT (2000) PDZ proteins interacting with C-terminal GluR2/3 are involved in a PKC-dependent regulation of AMPA receptors at hippocampal synapses. Neuron 28:873-886.

Doyle DA, Lee A, Lewis J, Kim E, Sheng M, MacKinnon R (1996) Crystal structures of a complexed and peptide-free membrane proteinbinding domain: molecular basis of peptide recognition by PDZ. Cell 85:1067-1076.

Ehlers MD (2000) Reinsertion or degradation of AMPA receptors determined by activity-dependent endocytic sorting. Neuron 28:511-525.

El-Husseini AE, Schnell E, Chetkovich DM, Nicoll RA, Bredt DS (2000) PSD-95 involvement in maturation of excitatory synapses. Science 290:1364-1368.

Garner CC, Nash J, Huganir RL (2000) PDZ domains in synapse assembly and signalling. Trends Cell Biol 10:274-280.

Hollmann M, Heinemann S (1994) Cloned glutamate receptors. Annu Rev Neurosci 17:31-108.

Kennedy MB (2000) Signal-processing machines at the postsynaptic density. Science 290:750-754.

Kim JH, Huganir RL (1999) Organization and regulation of proteins at synapses. Curr Opin Cell Biol 11:248-254.

Klugbauer N, Dai S, Specht V, Lacinová L, Marais E, Bohn G, Hofmann F (2000) A family of gamma-like calcium channel subunits. FEBS Lett 470:189-197.

Kornau H-C, Seeburg PH, Kennedy MB (1997) Interaction of ion channels and receptors with PDZ domains. Curr Opin Neurobiol 7:368-373.
Lee HK, Barbarosie M, Kameyama K, Bear MF, Huganir RL (2000) Regulation of distinct AMPA receptor phosphorylation sites during bidirectional synaptic plasticity. Nature 405:955-959.

Letts VA, Felix R, Biddlecome GH, Arikkath J, Mahaffey CL, Valenzuela A, Bartlett II FS, Mori Y, Campbell KP, Frankel WN (1998) The mouse stargazer gene encodes a neuronal $\mathrm{Ca}^{2+}$-channel $\gamma$-subunit. Nat Genet 19:340-347.

Liu SQ, Cull-Candy SG (2000) Synaptic activity at calcium-permeable AMPA receptors induces a switch in receptor subtype. Nature 405:454-458.

Lüscher C, Nicoll RA, Malenka RC, Muller D (2000) Synaptic plasticity and dynamic modulation of the postsynaptic membrane. Nat Neurosci 3:545-550.

Lüscher C, Xia H, Beattie EC, Carroll RC, von Zastrow M, Malenka RC, Nicoll RA (1999) Role of AMPA receptor cycling in synaptic transmission and plasticity. Neuron 24:649-658

Luthi A, Chittajallu R, Duprat F, Palmer MJ, Benke TA, Kidd FL, Henley JM, Isaac JT, Collingridge GL (1999) Hippocampal LTD expression involves a pool of AMPARs regulated by the NSF-GluR2 interaction. Neuron 24:389-399.

Madison DV, Malenka RC, Nicoll RA (1991) Mechanisms underlying long-term potentiation of synaptic transmission. Annu Rev Neurosci 14:379-397.

Malinow R, Mainen ZF, Hayashi Y (2000) LTP mechanisms: from silence to four-lane traffic. Curr Opin Neurobiol 10:352-357.

Man YH, Lin JW, Ju WH, Ju A, Liu L, Becker LE, Sheng M, Wang YT (2000) Regulation of AMPA receptor-mediated synaptic transmission by clathrin-dependent receptor internalization. Neuron 25:649-662.

Nakanishi S (1992) Molecular diversity of glutamate receptors and implications for brain function. Science 258:597-603.

Roche WK, O’Brien RJ, Mammen AL, Bernhardt J, Huganir RL (1996) Characterization of multiple phosphorylation sites on the AMPA receptor GluR1 subunit. Neuron 16:1179-1188.

Seeburg PH (1993) The TINS/TiPS lecture. The molecular biology of mammalian glutamate receptor channels. Trends Neurosci 16:359-365.

Sheng M, Sala C (2001) PDZ domains and the organization of supramolecular complexes. Annu Rev Neurosci 24:1-29.

Soderling TR (2000) CaM-kinases: modulators of synaptic plasticity. Curr Opin Neurobiol 10:375-380.

Song I, Kamboj S, Xia J, Dong H, Liao D, Huganir RL (1998) Interaction of the $N$-ethylmaleimide-sensitive factor with AMPA receptors. Neuron 21:393-400.

Srivastava S, Osten P, Vilim FS, Khatri L, Inman G, States B, Daly C, DeSouza S, Abagyan R, Valtschanoff JG, Weinberg RJ, Ziff EB (1998) Novel anchorage of GluR2/3 to the postsynaptic density by the AMPA receptor-binding protein ABP. Neuron 21:581-591.

Tomita S, Nicoll RA, Bredt DS (2001) PDZ protein interactions regulating glutamate receptor function and plasticity. J Cell Biol 153:F19-F24

Topinka JR, Bredt DS (1998) N-terminal palmitoylation of PSD-95 regulates association with cell membranes and interaction with $\mathrm{K}+$ channel, $\mathrm{K}_{\mathrm{v}} 1.4$. Neuron 20:125-134.

Xia J, Chung HJ, Wihler C, Huganir RL, Linden DJ (2000) Cerebellar long-term depression requires PKC-regulated interactions between GluR2/3 and PDZ domain-containing proteins. Neuron 28:499-510.

Ziff EB (1997) Enlightening the postsynaptic density. Neuron 19:11631174. 